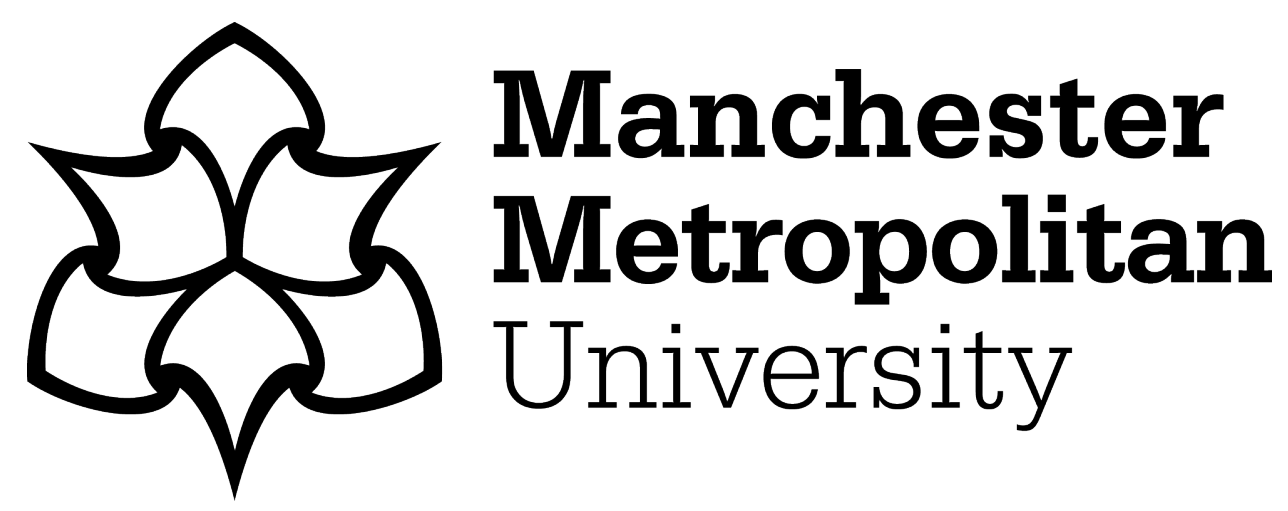

Forsyth, Rachel ORCID logoORCID: https://orcid.org/0000-0001-7401-2870 and Penny, Sweasey (2020) Myths and legends: changing assessment procedures and practices. In: Delivering Educational Change in Higher Education: A Transformative Approach for Leaders and Practitioners. SEDA Series . Routledge. ISBN 978-0-367-14784-6

Downloaded from: https://e-space.mmu.ac.uk/625239/

Version: Accepted Version

Publisher: Routledge

Please cite the published version 


\section{Whole institutional change: leaders in action}




\title{
Myths and legends: changing assessment procedures and practices
}

\author{
Rachel Forsyth and Penny Sweasey
}

\section{Introduction}

There is a fairly strong argument for suggesting that leaders of educational change might be wiser to avoid tackling assessment. In a general way, just thinking about change in assessment is challenging. Everyone involved with a university will have been assessed during their own formal education, as well as in their professional lives, and their experiences, particularly of assessment as a gatekeeper to future aspirations, may still be vivid and influential. It is difficult to leave these feelings behind when considering approaches that may be more appropriate to the expectations of students in a modern university.

These very personal feelings about assessment may be combined with institutional anxiety about the reputational risk associated with reviews of assessment. Collins (2014: 1) notes that,

Effective leadership in any organization relies on persuasion, but this is especially true in . . universities. Any effort to encourage . . . leadership will fail unless it is sensitive to the distinctive challenges of higher education's individualistic culture.

Members of teaching staff may express fear that change, such as experimenting with alternatives to traditional tasks, will disadvantage students, or that standards will be unintentionally lowered, or perhaps raised, in ways which are unacceptable (Forsyth and Cullen, 2016). They may worry that new forms of providing feedback may not achieve intended purposes; from their connections with professional bodies, they may know that a move away from unseen examinations will affect external accreditations.

Students may also worry about moving away from time-honoured approaches to their assessment. They may express this in their feedback. The UK National Student Survey has a particular section on assessment, and it has an impact on various league tables as well as the national ratings given by the Teaching Excellence Framework.

This chapter reflects on an institution-wide review of assessment practice, partly supported by Jisc through their assessment and feedback programme, 
which sought a more effective framework for managing and leading change in assessment practice (Forsyth et al, 2015) and discusses the extent to which these kinds of fears are rooted in institutional 'myths and legends' which might be replaced with more empowering leadership narratives.

Manchester Metropolitan is a large, diverse UK university with more than 30,000 students, which offers courses in a very wide range of disciplinary areas. The institution has had its own degree-awarding powers since 1992, meaning that before then, it was subject to a national accreditation system (the Council for National Academic Awards, CNAA). Whilst the university is not exceptional in this situation, it is relevant to discussion of assessment change because it means that it has a relatively short history of self-management of quality regulations and procedures, and these have been developed in parallel with a national system for quality oversight which may be perceived to be as prescriptive as the system which preceded it. Management of assessment has to consider the diversity of provision, with around 70 professional bodies accrediting courses and providing their own norms and expectations for assessment practices. Inevitably, the expectations of these external bodies have an impact on beliefs about appropriate quality standards and processes.

Although this institution serves as a case study here, it is not unique in experiencing tensions around assessment. The UK National Student Survey (NSS) shows that students are about $10 \%$ less satisfied with assessment and feedback than with their courses overall (Burgess et al, 2018; Higher Education Funding Council for England (HEFCE), 2014; Sturridge, 2008). The relatively poor performance of the 'assessment and feedback' items in the NSS has generated a strong focus on the area in UK Higher Education since the late 2000s (e.g., Bótas and Brown, 2013; Williams et al, 2008; Yorke, 2013).

The nature of the questions asked in the National Student Survey about assessment (Table 11.1) does not provide a clear steer to leaders about the changes they should implement, it only highlights dissatisfaction.

A scan of 'hot topics' on professional network discussion mailing lists or relevant conference themes shows that leaders at all levels are still seeking reassurance about best practice and sector norms (and indeed finding the 'norms' hard to pin down). Internationally, the need to prepare a more diverse student body for societies which are rapidly changing continues to drive discussion about assessment design and management.

Table II.I Assessment and feedback questions in UK National Student Survey (questions 8-1I of 27)
8. The criteria used in marking have been clear in advance.
9. Marking and assessment has been fair.
10. Feedback on my work has been timely.
II.I have received helpful comments on my work. 


\section{A baseline review of assessment}

A multi-professional project team was formed, including teaching staff, learning technologists, and educational developers. The project was sponsored by the Deputy Vice-Chancellor and had a steering group of senior leaders. The team began with a thorough review of existing assessment practices, with a wide range of questions posed about the nature of assessment design and the perceived barriers to change, if any. Data were collected using mixed methods: desk reviews of institutional grey literature; analysis of data relating to assessment such as student surveys, student outcomes, progression data, the range of assignment tasks in use; reviews of academic appeals; interviews and focus groups with a cross-section of academic and professional services staff across the institution (Forsyth et al, 2015).

The analysis of tasks showed that there was a clustering of assessment types in the institution. Despite the wide diversity of disciplinary areas, at level 6 (the final year of an undergraduate degree in the UK), 60\% of the 1606 distinct assignments were described as one of three types: examination, essay or dissertation/project report. When asked, course teams were generally unable to identify positive reasons for this consistency of design, other than beliefs that these were the preferred choices of the university. The review of institutional guidance and regulation did not have any direction or suggestions about the types of assignment task, so these beliefs were not founded in fact, but it is possible that the absence of specific support led to a reliance on custom and practice.

There was also anxiety about correct procedures. During one interview, one head of department asked the interviewer, who was perceived to know more about institutional rules than the head of department themselves, 'is a parallel paper-based submission required/essential as a back-up [to online submission]?' Clearly, academic leaders required both confidence and a sense of autonomy/ entitlement to take the reins of assessment design more fully. Another explained very convoluted processes for managing assessment, which they believed to be necessary to comply with institutional requirements; there was no institutional policy which would have required this complex, and resented, series of actions.

The difficulty of modifying existing assessments was also often characterised as a problem of power balance: 'Professorial colleagues have very high status and hold significant power but ... their approach to teaching learning and assessment can be very "old school"'. This interviewee, a fairly junior programme team member, did not feel that they had agency to change practice. Some new teaching staff, studying for the institutional teaching qualification, expressed concern that they were unable to change assessment methods due to institutional rules, or because there was an aversion to change in their department. This created a tension for them between the developmental and explorative activity they encountered in their teaching course, which exposed them to new ways of conceiving assessment practice, purpose, and philosophy, and the 'business as usual' approach encountered in their home departments, where workload and communications made change a challenge. 
The expectations of professional, statutory, and regulatory bodies (PSRBs), who provide additional accreditation and professional recognition for qualifications, were also cited as barriers to change in the types of assessment (e.g., Broadbent and McCann, 2016; Eva et al, 2016; Forster et al, 2017; Musekamp and Pearce, 2016).

Overall, the picture was one of competence in assessment, but an inability to innovate to respond quickly to the demands of a diverse sector or to changes in graduate requirements. The project team decided to review the entire system of assessment management throughout its lifecycle from design of tasks to completion of marking (grading) processes.

\section{The leadership of assessment change}

The notion of a definitive reference point had permeated many of the interviews and focus groups in the baseline review and had a critical impact on the way we chose to approach the challenges of anxiety and uncertainty in relation to assessment change. Rather than create a more comprehensive rule book, we decided to try to move to a culture in which leaders and their academic teams felt that they had more agency and responsibility for their assessment choices.

We wanted to move from an institution where people asked, 'Am I allowed to...?' to one in which they asked, 'How do I implement this innovative approach to assessment?'. Instead of basing their practice on institutional myths and legends, we wanted teams to create their own narratives about how assessment should be carried out in their courses. In the rest of the chapter, we will identify some of the key steps we took to develop an approach to assessment which prioritised academic decision-making.

Whilst the project team had formed a clear objective, we knew the leadership of such change would be challenging. Armstrong (2016) identified two key issues in this culture of reluctance or resistance: the danger of disturbing a 'delicately balanced interacting network' and a fear of undermining existing good practice by introducing a disruptive change, perhaps by mistake.

Bryman (2007) pointed out the importance of collegiality in effective university leadership, and also suggested that leaders need to show trust and confidence in the professionalism of their staff. This theme was picked up by Burnes, Wend and By (2014: 915) who state that,

academics [teaching staff] tend to question what is put in front of them; they tend to value consultation (but not as a tick-the-box exercise) and the ability to analyse and question decisions. Consequently, in universities, as in most other organisations, involving staff in change is vital for gaining the commitment to making it work.

From a leadership perspective, the key factor was the decision to move from instructions to principles. This was an approach which challenged institutional 
expectations. The pre-1992 validation arrangements had normalised detailed directives on all quality matters. Whilst these had been largely removed, there was a strong culture of reference to what were now mythical regulations. In general, participants in the baseline research had requested more rules, rather than fewer. It can be difficult to resist such pressure, but we judged that proliferation of more directive rules would be likely to lead to more anxiety about how to interpret such rules accurately. The literature about assessment literacy and the processes of grading and feedback (e.g., Bloxham, 2009; Bloxham et al, 2015; Bloxham et al, 2015; Carless et al, 2011; Nicol and Macfarlane-Dick, 2006; Price et al, 2011; Price et al, 2012), indicates that increasing the confidence of teaching staff to make their own assessment decisions would be more effective in achieving meaningful change than telling them how to do it.

However, moving to a system which empowered teaching staff to take more of their own assessment decisions represented a significant cultural change for a large institution with a relatively recent history of degree-awarding independence. A key aspect of achieving this was in changing the discourse of academic development. The team took a conscious decision to frame all discussion in terms of the empowerment of teaching staff. For example, in terms of designing new assignments, course teams were encouraged to ask five questions about their proposed assessment tasks:

1 Will students be able to demonstrate achievement of the learning outcomes?

2 Will I look forward to marking it?

3 Will students understand what to do?

4 Can I link it clearly to the proposed content?

5 Will it be straightforward to mark and moderate?

These questions supported discussions about aspiration, feasibility, and enjoyment of assessment. Before the project, many questions about assessment began with 'Am I allowed to?'. Wherever possible, questions about assessment design were answered with 'That's an academic decision to be made by the course team, and here are some further questions which may help you to make a decision'.

Workshops were organised by suggesting changes to assessment which might be perceived as radical or disruptive, and then working through the decision process to decide whether such an action would work in the context of the participants' programmes, or not. The outcome, in terms of a set of principles, was that Heads of Department and programme leaders had a manifesto for their assessment approach, and permission to innovate and introduce variety, whilst maintaining coherence at a programme level.

Many of the institutional myths seemed to be based in people's understandings of the regulations and procedures relating to assessment. The project therefore began by ensuring that these were as clear as possible, and promoted an evidence-based approach to assessment design and management. For example, in the new procedures, very clear definitions about the purpose and management 
of moderation were given, together with guidance on how to decide on a sample of work to be reviewed; the exact focus of moderation and the number of submissions to be included in the sample was left to the discretion of the course team. It was also made clear that this decision might be changed from year to year; for example, if the team had new members of staff who were inexperienced in marking that kind of assignment, or if the previous year's moderation had shown excellent practice, then the sample might be reduced the next year (or vice versa). The point was to encourage discussion about the value and impact of moderation in relation to assessment practice and improving assessment literacy across the board (Bloxham et al, 2015; Zahra et al, 2016).

Using the new procedures, teams were asked to be consistent in approach so that students having the same task marked by different markers, or different assignment in different units, would see something similar in style to each other, but it was made clear that the final decisions were theirs. The procedures were then presented through normal institutional governance processes and were followed up by the development of extensive supporting resources and a campaign of staff development which focused on the role of academic decision-making rather than institutional instructions.

The next stage was to roll out information about the new procedures. A suite of web pages and staff development resources was designed by the educational development team to support this, and the project team attended university and departmental meetings, provided a programme of workshops in each of the faculties, as well as designing an accredited module on the university's compulsory teaching qualification, and answering questions as they arose.

\section{Impact}

By their nature, these kinds of cultural change projects can be difficult to evaluate. This project involved stakeholders from across the university: academic developers, quality managers, students' union, student services, management services, information systems developers, technology-enhanced learning specialists, and programme leaders. Everyone played a different part in changing the discourse about assessment and implementing changes to practice. The most effective changes in practice seemed to come about when innovation was at a course or departmental level, and not an isolated change. Students will inevitably compare tutors' approaches across modules, but a consistent approach, with a clear rationale, clearly communicated to students at the outset of their studies gave everyone (staff and students) confidence in the approach. This approach has continued to be supported through educational development and changes in approaches to other institutional procedures such as course approval and review.

Some aspects of improvement in relation to assessment could be measured: numbers of staff engaging in voluntary assessment-related staff development; a marked and sustained change in student satisfaction with assessment; an increase 
in the diversity of assignment types in use; comments from external examiners about practice and external assessors about new course designs; a reduction in academic appeals about assessment decisions. Following the project, these have all showed improvements, but they are essentially proxy measures for change.

After six years, student satisfaction with assessment and feedback across the institution, as indicated in the NSS was $74 \%$ compared to $63 \%$ at the beginning of the project (national figures were $73 \%$ and $67 \%$, respectively). This shows a faster improvement in satisfaction in the institution than has happened in the sector as a whole, although there is still much work to do to close the gap between this aspect and overall satisfaction.

Ideally, a follow-up study would ask questions about people's confidence with assessment and their attitudes towards making and managing assessment decisions. This was not factored in to the original project because the initial scope did not anticipate the importance of the cultural issues in bringing about change.

\section{Conclusion and reflections}

Leading change in assessment is a particular challenge. Assessment affects almost everyone in the institution, and proposing significant modification to assessment practice can make people very anxious, and assessment literacy among this wide range of stakeholders cannot be assumed. We found a great deal of reliance on previous experiences rather than evidence-based decision-making. Institutional myths may be a significant barrier to innovation; these will vary, of course, between institutions, but we found it valuable to identify and confront these wherever possible.

In order to overcome these very reasonable fears about making changes which may affect students' success in higher education, careful support is needed. Teaching staff need to feel that they have the right to be innovative, and help with thinking through the implications of change. Students need to be able to trust in alternative ways of being assessed and learn how non-traditional tasks may be helpful to them in the future. Professional services staff need to know how to manage submissions, grading, and moderation when there is a move away from what they are used to. We found that we were able to provide support for this wide range of stakeholders by reviewing regulations for clarity and reinforcing the purpose and process of academic decision-making throughout the university's governance structures. Giving people confidence to make their own changes was key to finding ways to make assessment more authentic and to reduce people's anxiety about innovating in this area.

\section{References}

Armstrong, L. (2016) Barriers to innovation and change in higher education. Retrieved from https://www.tiaainstitute.org/sites/default/files/presentations/2017-03/Armstrong Barriers $\% 20$ to $\% 20$ Innovation $\% 20$ and $\% 20$ Change $\% 20$ in $\% 20$ Higher $\% 20$ Education.pdf 
Bloxham, S. (2009) Marking and moderation in the UK: false assumptions and wasted resources. Assessment \& Evaluation in Higher Education, 34(2), 209-220. doi:10.1080/02602930801955978.

Bloxham, S., den-Outer, B., Hudson, J., and Price, M. (2015) Let's stop the pretence of consistent marking: exploring the multiple limitations of assessment criteria. Assessment \& Evaluation in Higher Education, 1-16. doi:10.1080/02602938.2015. 1024607.

Bloxham, S., Hudson, J., den Outer, B. and Price, M. (2015) External peer review of assessment: an effective approach to verifying standards? Higher Education Research \& Development, 34(6), 1069-1082. doi:10.1080/07294360.2015.1024629.

Bloxham, S., Hughes, C. and Adie, L. (2015) What's the point of moderation? A discussion of the purposes achieved through contemporary moderation practices. Assessment \& Evaluation in Higher Education, 1-16. doi:10.1080/02602938.2015.1039932.

Bótas, P. C. P. and Brown, R. (2013) The not so "Holy" Grail: the impact of NSS feedback on the quality of teaching and learning in higher education in the UK. Enhancing Student Feedback and Improvement Systems in Tertiary Education, 46.

Broadbent, O. and McCann, E. (2016) Experience-led learning for engineers-A good practice guide. Retrieved from London: Royal Academy of Engineering. Retrieved from https://www.raeng.org.uk/publications/reports/experience-led-learning-for-engineers [Accessed 16.11.19].

Bryman, A. (2007) Effective leadership in higher education: a literature review. Studies in Higher Education, 32(6), 693-710.

Burgess, A., Senior, C and Moores, E. (2018) A 10-year case study on the changing determinants of university student satisfaction in the UK. PLOS ONE, 13(2), e0192976. doi:10.1371/journal.pone.0192976.

Burnes, B., Wend, P. and By, R. T. (2014) The changing face of English universities: reinventing collegiality for the twenty-first century. Studies in Higher Education, 39(6), 905-926. doi:10.1080/03075079.2012.754858.

Carless, D., Salter, D., Yang, M. and Lam, J. (2011) Developing sustainable feedback practices. Studies in Higher Education, 36(4), 395-407.

Collins, J. P. (2014) Leadership and change in twenty-first century higher education. BioScience, 64 (7), 561-562. doi:10.1093/biosci/biu080.

Eva, K. W., Bordage, G., Campbell, C., Galbraith, R., Ginsburg, S., Holmboe, E. and Regehr, G. (2016) Towards a program of assessment for health professionals: from training into practice. Advances in Health Sciences Education, 21(4), 897-913. doi:10.1007/ s10459-015-9653-6.

Forster, A. M., Pilcher, N., Tennant, S., Murray, M., Craig, N. and Copping, A. (2017). The fall and rise of experiential construction and engineering education: decoupling and recoupling practice and theory. Higher Education Pedagogies, 2(1), 79-100. doi:10.1080/ 23752696.2017 .1338530$.

Forsyth, R. and Cullen, R. (2016) You made me fail my students!. Paper presented at the SEDA Spring Learning and Teaching Conference, Edinburgh.

Forsyth, R., Cullen, R., Ringan, N. and Stubbs, M. (2015) Supporting the development of assessment literacy of staff through institutional process change. London Review of Education, 13 (34-41).

Higher Education Funding Council for England (HEFCE) (2014) UK review of the provision of information about higher education: National Student Survey results and trends analysis 2005-2013. Retrieved from Bristol: ht+n://www.hefce.ac.uk/media/ 
hefce/content/pubs/2014/201413/HEFCE2014_13\%20-\%20corrected\%2012\%20 December\%202014.pdf

Musekamp, F. and Pearce, J. (2016) Student motivation in low-stakes assessment contexts: an exploratory analysis in engineering mechanics. Assessment \& Evaluation in Higher Education, 1-20. doi:10.1080/02602938.2016.1167164.

Nicol, D. and Macfarlane-Dick, D. (2006) Formative assessment and self-regulated learning: a model and seven principles of good feedback practice. Studies in Higher Education, 31(2), 199-218.

Price, M., Carroll, J., O'Donovan, B. and Rust, C. (2011) If I was going there I wouldn't start from here: a critical commentary on current assessment practice. Assessment \& Evaluation in Higher Education, 36(4), 479-492.

Price, M., Rust, C., O’Donovan, B., Handley, K. and Bryant, R. (2012) Assessment literacy: the foundation for improving student learning: ASKe, Oxford Centre for Staff and Learning Development.

Sturridge, P. (2008) The National Student Survey 2005-2007: Findings and Trends. Retrieved from ht+n://www.hefce.ac.uk/pubs/rdreports/2008/rdl2_08/

Williams, J., Kar (-) and Sagu, S. (2008) Exploring the National Student Survey Assessment and feedback issues. The Higher Education Academy, Centre for Research into Quality.

Yorke, M. (2013) Surveys of 'the student experience' and the politics of feedback. Reconceptualising Feedback in Higher Education, 6-18.

Zahra, D., Robinson, I., Roberts, M., Coombes, L., Cockerill, J. and Burr, S. (2016). Rigour in moderation processes is more important than the choice of method. Assessment o Evaluation in Higher Education, 1-9. doi:10.1080/02602938.2016.1236183.

\section{Reader's response}

\section{Jessica Riddell}

Orchestrating institutional culture change is a complex undertaking, especially when it comes to pedagogical shifts that have implications on faculty workload, student success, and even institutional reputation - as is the case with assessment. The authors provide a very timely intervention, starting with a thorough overview of the negative perceptions around shifts in assessment practices from a number of perspectives. Within a Canadian context, universities are not subject to the same external/governmental systems and accreditation bodies such as the UK National Student Survey, league tables, or the national ratings given by the Teaching Excellence Framework. However, the Canadian landscape of postsecondary education is facing increasing pressures that parallel the challenges within the UK system: Maclean's Magazine University Rankings create a league table that is influential for prospective students and their parents. Furthermore, higher education is a provincial constitutional responsibility rather than national system, which makes for variation in provincial funding formulas. Some provinces are in the process of adopting performance-based metrics for funding, which makes this chapter a timely contribution to data-driven discussions about assessment at the institutional level. 
The authors of this study do an excellent job of exploring implications of power balances between faculty and academic leaders around perceptions of autonomy, entitlement, and confidence in relation to assessment design. They contribute to current research on leadership and its effect on institutional change and operations (cf. Miller-Young et al, 2017). Kezar (2012) examines institutional culture change in higher education and how the groups of staff, administrators, and faculty conceive of and interact over change agendas. The interaction between bottom up leadership and top down leadership generates dynamics of convergence, which has a direct effect on how successful a grassroots movement is in broadening and institutionalizing their work. Kezar defines convergence as joining efforts between grassroots and individuals in positions of authority, and convergence can happen in either direction. As Forsyth and Sweasey prove that multi-pronged and nuanced approaches to institutional culture change lead to more complex solutions and ideas, more buy in, more energy and enthusiasm, more consensus, and a breadth and depth of expertise that benefits students. Grassroots movements can also have the potential outcome of deeper and more transformational change within a shorter timeframe and can build the leadership capacity of the organization (Roxå, 2014; Roxå and Mårtensson, 2009).

For there to be successful shifts to assessment - and institutional change more generally - design principles must include empowerment.

\section{References}

Kezar, A. (2012) Bottom-Up/Top down leadership: contradiction or hidden phenomenon. The Journal of Higher Education, 83(5), 725-760.

Miller-Young, J. E., Anderson, C., Kiceniuk, D., Mooney, J., Riddell, J., Schmidt Hanbidge, A., Ward, V., Wideman, M. A. and Chick, N. (2017) Leading up in the scholarship of teaching and learning. The Canadian Journal for the Scholarship of Teaching and Learning, 8(2). https://ojs.lib.uwo.ca/index.php/cjsotl_rcacea/article/ view $/ 7008 / 5722$ [Accessed 15.11.19]

Roxå, T. (2014) Microcultures in the Meso Level of Higher Education Organisations - The Commons, the Club, the Market, and the Square. Lund, Sweden: Lund University.

Roxå, T. and Mårtensson, K. (2009) Significant conversations and significant networks -exploring the backstage of the teaching arena. Studies in Higher Education, 34(5), $547-559$. 